\title{
GC/MS analysis of morning glory seeds freely in commerce: can they be considered "herbal highs"?
}

\author{
Isabella Mercurio ${ }^{1 *}$, Paola Melai ${ }^{2}$, Daniele Capano ${ }^{1}$, Gianluigi Ceraso ${ }^{3}$, Luigi Carlini ${ }^{4}$ and Mauro Bacci ${ }^{3}$
}

\begin{abstract}
Background: The so-called "herbal highs" are substances derived from natural plants with effects on the central nervous system. Lisergamide, ergine or LSA is the basis of different types of drugs, which are in seeds of Ipomoea violacea, also known as Morning Glory, and other seeds.

In our study we analysed the presence of lysergic acid amide (LSA) in seeds of Ipomoea violacea seized by the Italian Police, in others purchased through the Internet, and in other varieties of Ipomoea sold for ornamental purposes, to assess whether the actual consumption of ornamental seeds could contain hallucinogenic doses of LSA.
\end{abstract}

Methods: The analyses were conducted at the Laboratory of Forensic Toxicology of the Section of Legal Medicine of the University of Perugia, using GC/MSD system. For analysis, $300 \mathrm{mg}$ of seeds ( $~ 8$ seeds) from each specimen were chosen.

Results: Analysis revealed that $300 \mathrm{mg}$ of Ipomoea violacea seeds resulting from police seizures, equivalent to approximately 8 seeds, contained a percentage of LSA equal to $0.062 \%$. This finding is in agreement with what was indicated in literature, as the ingestion of 250 seeds would lead to a dose of approximately $6 \mathrm{mg}$ of LSA, capable of provoking hallucinogenic effects.

The analysis of $300 \mathrm{mg}$ of Ipomoea Rubrocerulea seeds bought on the commercial marketdetected an average concentration of LSA of $0.011 \%$. The Ipomoea mix contained a concentration of LSA about 10 times lower than that of seized Morning Glory seeds.

Conclusion: Seeds bought on the commercial market contained doses of LSA capable of provoking hallucinogenic effects. In the absence of data on the toxicity resulting from the ingestion of seeds for ornamental purposes, we believe that further research on the actual safety of ornamental seeds is necessary.

Keywords: Herbal highs, Legal highs, Ipomoea, Lysergamide, Ergine, Lsa, Morning-glory

\section{Background}

In recent years, interest in non-conventional drugs has increased. The so-called "herbal highs" are substances derived from natural plants with effects on the central nervous system (Halpern, 2004; Bilgrey, 2016; Zuba et al., 2011).

These drugs are called "legal highs", underlining the fact that they have easy accessibility, low cost, and are not illegal (Aoun et al., 2014).

Lisergamide (Juszczak \& Swiergiel, 2013), ergine or LSA is the basis natural drugs, which are contained in

\footnotetext{
* Correspondence: isabmerc@gmail.com

${ }^{1}$ Forensic Medicine, Department of Medical Sciences, Surgical and Neurosciences, University of Siena, Hospital Santa Maria alle Scotte, 1 Viale Bracci, 53100 Siena, Italy

Full list of author information is available at the end of the article
}

brown seeds of Rivea Corymbosa, of Ipomoea violacea also known as Morning Glory and of Argyreya Nervosa known as Hawaiian Baby Woodrose. These plants are members of Convulacee family and are infected by a kind of clavicipitaceus fungus that is responsible for the biosynthesis of alkaloids. The most important alkaloids are ergine and isoergine, which is ergine enatiomer. In these seeds, other bases especially chanoclavine, elymoclavina, and lysergol can also be found.

Studies on seeds of Morning Glory began in 1955 when a psychiatrist published notes on self-experimentation with Rivea seeds, showing that they provoked hallucinations. This announcement prompted chemists to analyse this plant, but until 1960 they failed to identify the active 
substance. At that time the chemist Hoffmann Albert (Hofmann, 1963), who discovered LSD, analysed the plant and found several alkaloids closely related to that powerful synthetic hallucinogen.

The discovery of ergot alkaloids in seeds of Rivea Corymbosa, Ipomoea violacea and Argyreia nervosa in the early $60 \mathrm{~s}$ was rather unexpected and of particular interest from a phytochemical point of view, since the lysergic acid alkaloids, until then, were isolated only in the genus Claviceps fungus, Penicillium or Rhizopus (Steiner et al., 2006).

The ingestion of Ipomoea violacea seeds produces effects comparable to those produced by Argyreia nervosa seeds. These effects, although minor, are similar to those of LSD.

In general, seeds are ingested whole or broken and immersed in water. Data in literature suggest that in order to have the hallucinogenic effects, 10 seeds Argyreia nervosa (Al-Assmar, 1999), and from 150 to 200 seeds of Morning Glory are typically ingested (Schultes, 1960).

Ergine hallucinogenic activity (LSA) is carried out starting from the assumption of 2-5 mg (Schultes \& Hofmann, 1980). LSA effects, lasting about $4-8 \mathrm{~h}$, are associated with feelings of tranquility, dysphoria, psychedelic visual effects, color visions. In humans, the lethal dose is $14 \mathrm{mg} / \mathrm{kg}$.

In addition to desired effects, LSA has several side effects (Juszczak \& Swiergiel, 2013). In a recent review, different symptoms following the ingestion of these seeds were reported: the most troubling of them was suicidal ideation. In literature, anorexia, nausea, memory loss, dissociative reactions and schizophrenic relapse are the major psychotic adverse effects that may occur as a result of ingestion of the seeds. Furthermore, in the past fatal cases occurred after taking seeds containing LSA have been described (Gertsch \& Wood, 2003; Cohen, 1964; Brady, 1968; Ingram, 1964; Flach, 1967; Whelan et al., 1968). The ingestion of seeds was frequently associated with taking drugs such as cannabis and hashish (Hofmann, 1963). Interactions due to ingestion of Argyreia nervosa, Ipomoea violacea or Rivea Corymbosa and other drugs are still unknown. However it has been shown that the metabolism of LSD analogous is inhibited by drugs used in HIV therapy. This suggests the possibility that patients, treated with antiretroviral drugs, taking LSD or Argyreia nervosa, Ipomoea violacea or Rivea Corymbosa, may manifest an increase in the toxicity induced by such hallucinogens (Klinke et al., 2010).

In our study we tried to analyse the presence of lysergic acid amide in seeds of Ipomoea violacea seized by Italian Police, in others purchased through the Internet, and in other varieties of Ipomoea sold for ornamental purposes, to assess whether the actual intake of ornamental seeds could contain hallucinogenic doses of LSA. In addition we also evaluated and described the most suitable methods for the extraction and the quantitative determination of LSA (Mussof \& Daldrup, 1997).

\section{Methods}

The analyses were conducted at the Laboratory of Forensic Toxicology of the Section of Legal Medicine of the University of Perugia during May 2015. The reference standards used were purchased from the company Sigma - Aldrich and / or LGC Standards s.r.l.

Morning glory seeds (Fig. 1) used in the research were seized by the police during an operation for the prevention and suppression of illicit traffic of narcotic drugs and psychotropic substances, and delivered to the Forensic Toxicology Laboratory of the University of Perugia Section for the identification and qualitative and quantitative analysis.

Seeds of Heavenly Blue (Ipomoea Rubrocerulea) were bought on the internet from a site of ornamental plants; seeds of a mix of varieties of Ipomoea, purple and others were instead purchased directly in a shop for ornamental plants.

The chemical-toxicological analysis have been performed using GC / MSD system 6850/5973 Network, Agilent Technologies company, ion source connected to capillary HP5ms, $25 \mathrm{~mm}$ ID, column length $30 \mathrm{~m}$.

For analyses, $300 \mathrm{mg}$ of seeds ( $~ 8$ seeds) from each specimen were chosen. Each sample was washed with $3 \mathrm{ml}$ of distilled water and $2 \mathrm{ml}$ of dichloromethane, and then crushed in a mortar with quartz.

All the finely crushed material was collected in graduated glass tubes. Distilled water and a few drops of $1 \mathrm{~N}$ $\mathrm{NaOH}$ were added to obtain sharply basic $\mathrm{pH}$. Then the aqueous solution was extracted three times with a chloroform-methanol- $\mathrm{NH} 4 \mathrm{OH}$ solution in 9: 90: 1 aspect ratio. The extracts were dried under a stream of nitrogen at a temperature below $40{ }^{\circ} \mathrm{C}$. Finally $100 \mu \mathrm{l}$ of methanol RPE was added (Witters, 1975).

The LSA dilutions to obtain the calibration curve were prepared from a stock solution in methanol $(1 \mathrm{mg} / \mathrm{ml})$. The solution was diluted with methanol to obtain four concentrations of LSA included in a range between 10 and $100 \mu \mathrm{g} / \mathrm{ml}$ (Fig. 2) (Littlewood, 1970; Crawford, 1970).

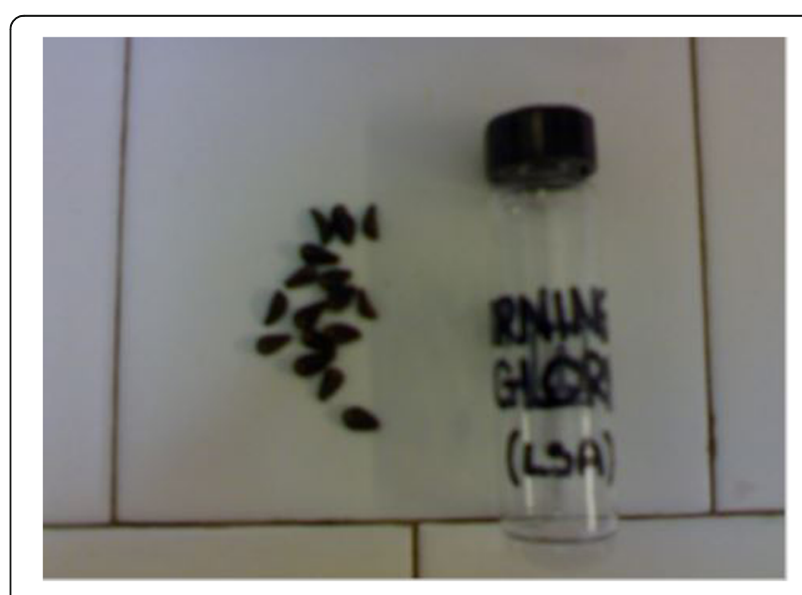

Fig. 1 Seized Seeds - Morning Glory 


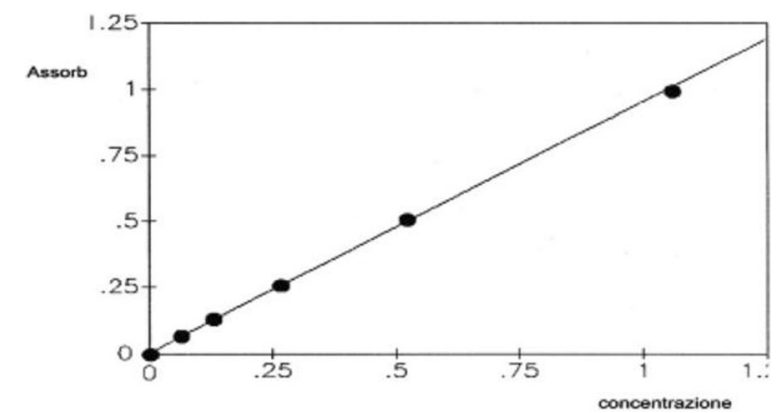

Fig. 2 Calibration Curve

The sample was introduced using splitless injection; programmed temperature for all analytes started at $150{ }^{\circ} \mathrm{C}$ for 2 mins, then, with a thermal gradient of $30{ }^{\circ} \mathrm{C}$ per min reached a temperature of $290{ }^{\circ} \mathrm{C}$ remaining constant for other 25 mins. Helium was used as carrier gas, setting a flow rate of $1 \mathrm{ml} / \mathrm{min}$ and the injector temperature was set at $280{ }^{\circ} \mathrm{C}$. The analytes, eluted from the chromatographic column, arrived via transfer line, whose temperature was set at $300{ }^{\circ} \mathrm{C}$, in the ionization source of the mass spectrometer, characterized by a temperature of $300{ }^{\circ} \mathrm{C}$. Here they were ionized through the 'application of a potential of $70 \mathrm{eV}$ and an emission of current of $200 \mathrm{uA}$. The characterization of all analytes was carried out in fullscan mode (range $\mathrm{m} / \mathrm{z}$ 50-800).

For quantitative analysis of LSA, MS-SIM acquisition mode was chosen; mass spectra were obtained by selecting at least three characteristic ions.

LSA wasidentified through its molecular ion m/z 267 and ion fragments 221 and 207. Analyses were repeated three times.

\section{Method validation}

The method linearity for each compound was investigated in the range $10-100 \mathrm{mcg} / \mathrm{ml}$. Calibration curves were established with three replicates at each concentration.

Sensitivity was evaluated by determination of the LOD and the limit of quantitation (LOQ). A series of decreasing concentrations of drug-fortified solutions was analysed to determine LOD and LOQ. The LOD was determined as the concentration with a signal/noise $(\mathrm{S} / \mathrm{N})$ ratio of at least 3 , while the LOQ was the lowest concentration with a S/N ratio of at least 10 . The acceptable value for the regression coefficient $(R 2)$ was set at $>$.98. $R 2$, LOD and LOQ values were respectively of $0.99671,5 \mathrm{ng} / \mathrm{ml}, 10 \mathrm{ng} / \mathrm{ml}$.

\section{Results and discussion}

All the used extractive methods revealed the presence of LSA in seeds of Ipomoea violacea, but the system with ammonium hydroxide, methanol and chloroform, provided excellent results in terms of yield compared to other systems adopted in preliminary screening tests. During fragmentation, the ion fragment $\mathrm{m} / \mathrm{z} 267$ had a value that was double, in terms of abundance ions, so it was used to quantify LSA. Chromatographic analysis revealed the presence of LSA in Ipomoea violacea seeds (Morning Glory), Ipomoea Rubrocerulea and Ipomoea mix (Figs. 3, 4 and 5).

Of the three varieties of Ipomoea investigated, the variety Ipomoea violacea showed a percentage of active ingredient $(\mathrm{LSA}=0.062 \%)$ significantly higher than the other two varieties.

In the variety of Ipomoea Rubrocerulea the active compound had been quantified around a mean value of $0.011 \%$, while in the mix the found value was still lower (around 0.006\%) (Table 1).

Currently the seeds of these plants can be purchased in smart shops or on the internet. In addition, these plants are usually sold as ornamentals. In this case, seeds are treated with chemical substances and antifungals. There are sites on the internet in which the users tell

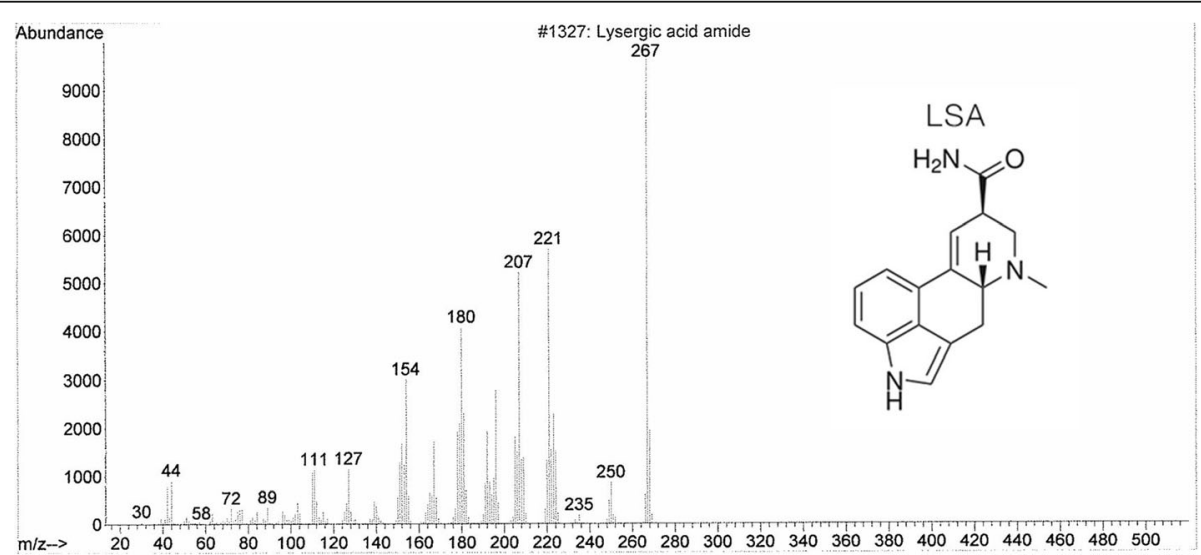

Fig. 3 Mass Spectrum LSA 


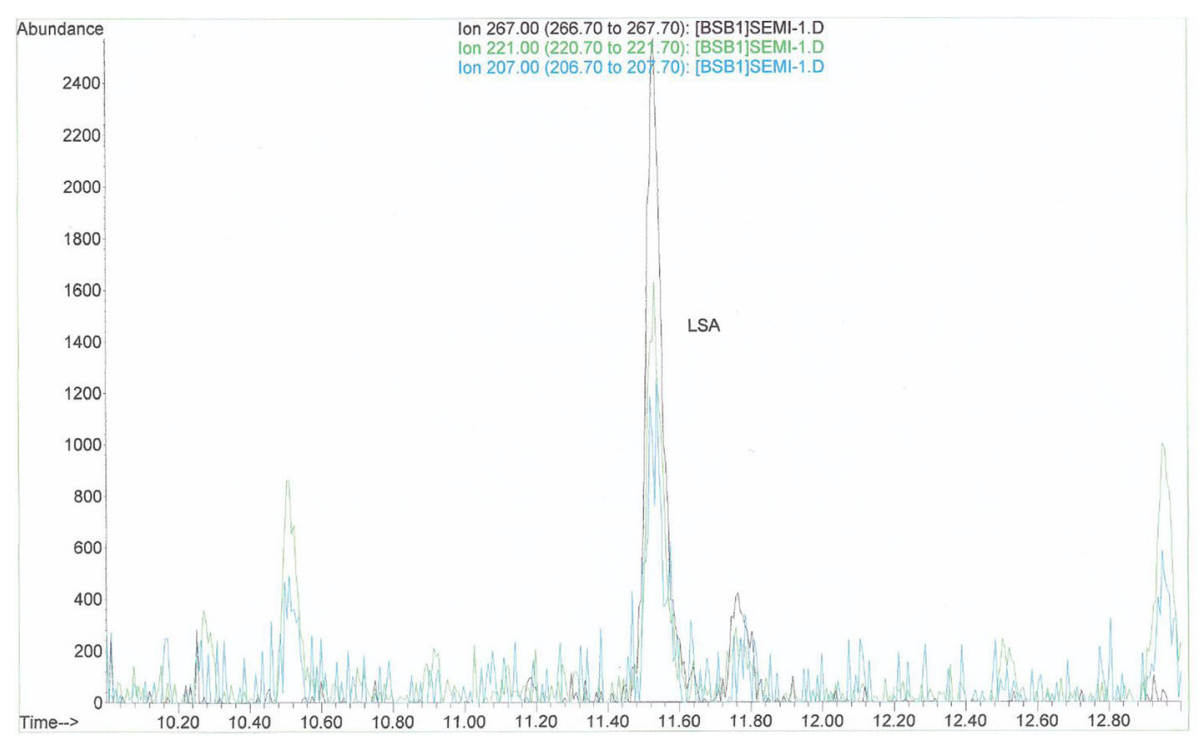

Fig. 4 Chromatograms of LSA from seed extracts

their experiences and explain how to extract LSA from ornamental seeds at home (Bilgrey, 2016).

The Italian law divides different drugs in various tables depending on their compounds. The decision to prohibit the spread of Salvia divinorum in 2005, another plant with psychoactive properties, was determined by few episodes of addiction. Since 2007, in Table 1, following an episode of suicide after ingestion, as a specific item, seeds of plants of Argyreia nervosa and Ipomoea viola$c e a$, containing as an active ingredient the lysergic acid amide were added to the table. Since 2014, the Italian law provided increased penalties for substances included in Tables 1 and 2, considered "hard drugs." Possession of Ipomoea violacea seeds and Argyreia nervosa, being present in Table 1 and, therefore, equated to the other hard drugs, could configure criminal behaviour, but ornamental seeds are freely sold.

Analysis revealed that $300 \mathrm{mg}$ of Ipomoea violacea seeds resulting from police seizures, equivalent to approximately 8 seeds, contained a percentage of LSA equal to $0.062 \%$. This finding is in agreement with what was indicated in the literature, as the ingestion of 250 seeds would lead to a dose of approximately $6 \mathrm{mg}$ of LSA, able to provoke hallucinogenic effects.

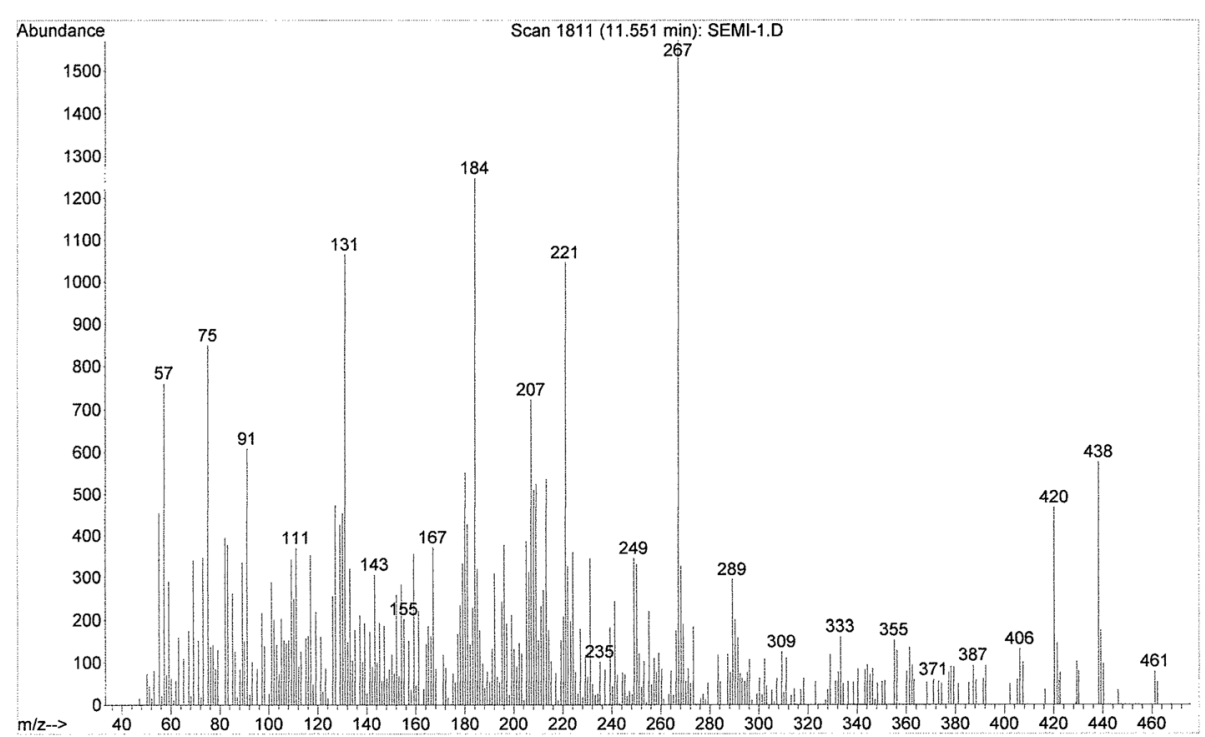

Fig. 5 Mass spectrum LSA from seed extracts 
Table 1 Concentration of LSA in analyzed seeds

\begin{tabular}{llll}
\hline LSA \% & Ipomoea violacea & Ipomoea Rubrocerulea & Ipomoea Mixture \\
\hline Analysis 1 & 0.062 & 0.012 & 0.006 \\
Analysis 2 & 0.075 & 0.011 & 0.007 \\
Analysis 3 & 0.048 & 0.009 & 0.006 \\
Medium & 0.062 & 0.011 & 0.006 \\
\hline
\end{tabular}

The analysis of $300 \mathrm{mg}$ of Ipomoea seeds detected an average concentration of LSA of $0.011 \%$, which means that in order to have the same hallucinogenic effects obtained by the ingestion of the seized seeds, a dose 6 times higher should be ingested.

The Ipomoea mix contained a concentration of LSA about 10 times lower than that of Morning Glory.

It is therefore possible to have hallucinogenic effects from Ipomoea seeds that are commonly marketed. However, the high amount of seeds that would need to be ingested to have the hallucinogenic effects would give considerable toxicity in the gastrointestinal tract, remember that each of these seeds is treated with fungicides and other toxic substances.

The strength of our work was the originality of the research and the sensitive and specific GC/MS method that ensured valid and reproducible results.

The most important limit was the small sample size. In addition, in our analysis we didn't investigate the presence of fungicides that are added to these seeds and other psychoactive substances, including alkaloids, often present in plants and which can affect the central nervous system.

In a social context that demonstrates a consistent rise in drug abuse (Isabella Mercurio et al., 2016a; Isabella Mercurio et al., 2016b; Stefania Milione et al., 2016), and increasing spread of herbal highs consumption, we believe that further studies are necessary to determine the toxic effects related to the ingestion of Ipomoea seeds and the related concentration of fungicide present on them, in order to understand if more restrictive measures would be necessary to control a possible spread of these seeds for abuse purposes.

\section{Conclusions}

In this work we identified the presence of LSA in all the Ipomoea seeds analysed. In the varieties used and sold for ornamental purposes, doses of LSA (0.011 and $0.006 \%$ ) were detected.

The detection of very different concentrations of LSA in all varieties of Ipomoea may be related to genetic and environmental factors, as well as intrinsic factors such as maturity and the age of the seeds of the same variety. All of these variables should be studied by increasing the number of seeds from different lots. In the absence of data on the toxicity resulting from the ingestion of seeds for ornamental purposes, especially that related to fungicides, we believe that further research on the actual safety of ornamental seeds is necessary, to assess if they can be considered as herbal highs.

\section{Acknowledgements}

The authors thank Dr. George Rettagliata, NY, for his valuable and precious contribution in the final revison of the article.

\section{Authors' contributions}

IM, DC, GC: literature review. PM: toxicological analysis IM, LC, MB: discussion and conclusions. All authors read and approved the final manuscript.

Funding

None.

Ethics approval and consent to participate

Not applicable.

Consent for publication

Not applicable.

\section{Competing interests}

The authors declare that they have no competing interests.

\section{Publisher's Note}

Springer Nature remains neutral with regard to jurisdictional claims in published maps and institutional affiliations.

\section{Author details}

${ }^{1}$ Forensic Medicine, Department of Medical Sciences, Surgical and Neurosciences, University of Siena, Hospital Santa Maria alle Scotte, 1 Viale Bracci, 53100 Siena, Italy. ${ }^{2}$ Hospital of Perugia, Perugia, Italy. ${ }^{3}$ Section of Legal Medicine, Forensic Science and Sports Medicine, University of Perugia, Perugia, Italy. ${ }^{4}$ Section of Forensic Medicine, Hospital of Terni, Terni, Italy.

Received: 15 May 2017 Accepted: 4 October 2017

Published online: 25 October 2017

\section{References}

Al-Assmar SE (1999) The seeds of the Hawaiian baby woodrose are a powerful hallucinogen. Arch Intern Med 27:2090

E. Aoun, P. Christopher, J. Ingraham (2014) Emerging drugs of abuse: clinical and legal considerations. R I Med J 97(6):41-5

OR Bilgrey (2016) From "herbal highs" to the "heroin of cannabis": Exploring the evolving discourse on synthetic cannabinoid use in a Norwegian Internet drug forum. Int J Drug Policy 29:1-8

Brady ET Jr (1968) A note on morning glory seed intoxication. Am J Hosp Pharm 25(2):88-89

Cohen S (1964) Suicide following morning glory seed ingestion. Am J Psychiatr 120:1024-1025

Crawford K.W. (1970) The identification of lysergic acid amide in baby Hawaiian woodrose by mass spectrometry. J Forensic Sci 15(4):588-94

Flach C (1967) A case of morning-glory-(ipomoea)-seed psychosis. Nordisk Psykiatrisk Tidsskrift 21(4):313-321

Gertsch JH, Wood C (2003) Case report: an ingestion of Hawaiian baby Woodrose associated with acute psychosis. Hawaii Med J 62:127-129

Halpern JH (2004) Hallucinogens and dissociative agents naturally growing in the United States. Pharmacol Ther 102:131

Hofmann A (1963) The active principles of the seeds of Rivea Corymbosa and Impomoea Violacea. Bot Museum Leaflets Harvard Univ 20(6):194-212

Ingram AL Jr (1964) Morning glory seed reaction. J Am Med Assoc 190: 1133-1134

Isabella Mercurio GT, Melai P, Agostinelli V, Simone R, Nante N, Bacci M (2016a) The analysis of the keratin matrix as a new tool to evaluate the epidemiology of drug use in Perugia (Italy): a cross sectional study. Epidemiol Biostatistics Public Health 13(2):e11732-11731/11737 
Isabella Mercurio, G. T., Paola Melai, Monica Zappulla, Veronica Agostinelli, Nicola Nante, Mauro Bacci (2016b) A 10 year post-mortem analysis of keratin matrix in Perugia (Italy): focus on cocaine involvement in several types of death. Aust J Forensic Sci. DOI: 10.1080/00450618.00452016.01264479.

Grzegorz R. Juszczak \& Artur H. Swiergiel (2013) Recreational Use of DLysergamide from the Seeds of Argyreia nervosa, Ipomoea tricolor, Ipomoea violacea, and Ipomoea purpurea in Poland. J Psychoactive Drugs 45(1):79-93

Klinke H, Muller I, Steffenrud S, Soresen R (2010) Two cases of. Lysergamide intoxication by ingestion of seeds from Hawaiian baby Woodrose. Forensic Sci Int 197

Littlewood AB (1970) Gas chromatography: principles, techniques and applications, 2nd edn. Academic Press, New York

Mussof F, Daldrup T (1997) Gas chromatographic/mass spectrometric determination of lysergic acid diethylamide (LSD) in serum samples. Forensic Sci Int 88:133-140

R.E. Schultes (1960) The Pharmaceutical Sciences, Third. Lecture Series, Part V University of Texas, Austin pp. 38-185

R.E. Schultes, A. Hofmann (1980) The Botany and Chemistry of Hallucinogens, 11 Springfield, IL, American Lecture Serie (USA)

Stefania Milione, I. M., Gianmarco Troiano, Paola Melai, Veronica Agostinelli, Nicola Nante, Mauro Bacci (2016) Drugs and psychoactive substances in the Tiber River. Aust J Forensic Sci. DOI: 10.1080/00450618.00452016.01212270.

Steiner U, Ahimsa-Müller MA, Markert A, Kucht S, Groß J, Kauf N et al (2006) Molecular characterization of a seed transmitted clavicipitaceous fungus occurring on dicotyledoneous plants Convolvulaceae. Planta 224(3):533-544

Whelan FJ, Bennett FW, Moeller WS (1968) Morning glory seed intoxication: a case report. J lowa Med Soc 58(9):946-948

Witters W.L., (1975) "Extraction and identification of Clavine and Lysergic Acid Alkaloids from morning glories", Department Of Zoology And Microbiology, Ohio University, Athens, Ohio 45701

D. Zuba, B. Byrska, M. Maciow (2011) Comparison of "herbal Highs" composition. Anal Bioanal Chem 400(1):119-126

\section{Submit your manuscript to a SpringerOpen ${ }^{\circ}$ journal and benefit from:}

- Convenient online submission

- Rigorous peer review

- Open access: articles freely available online

- High visibility within the field

Retaining the copyright to your article

Submit your next manuscript at $\boldsymbol{\triangleright}$ springeropen.com 